\title{
A Study on the Gender Digital Divide: Overcoming the Under-Representation of South African Women in the IT Sector
}

\author{
Tengudzeni Nkosingiphile Mamba \\ Graduate School of Business, Asia Pacific University of Technology and Innovation, \\ 57000 Kuala Lumpur, Malaysia \\ E-mail: tenguwamamba@gmail.com
}

\begin{abstract}
Seetha Nesaratnam (corresponding author”
Senior lecturer, Asia Pacific University of Technology and Innovation, Jalan Teknologi 5, Taman Teknologi Malaysia, 57000 Kuala Lumpur, Malaysia

Tel: 603-8996-1000Ｅ-mail: seethahunt.n@gmail.com

Jugindar Singh Kartar Singh

Senior lecturer, Asia Pacific University of Technology and Innovation, Jalan Teknologi 5, Taman Teknologi Malaysia, 57000 Kuala Lumpur, Malaysia

Tel: 603-8996-1000Ｅ-mail: jugindar.singh@apu.edu.my
\end{abstract}

Received: April 10, 2017 Accepted: May 8, $2017 \quad$ Published: December 31, 2018

doi:10.5296/bms.v9i2.13376

URL: https://doi.org/10.5296/bms.v9i2.13376

\begin{abstract}
In South Africa, women are grossly underrepresented in the Information Technology (IT) sector result of gender stereotyping and discrimination. According to the Independent Communications Authority of South Africa (ICASA) Report (2017), only 21\% of executives in the IT sector are women. This has caused high unemployment of women IT graduates. The purpose of this study therefore is to explore and investigate the antecedents that influence and impact the phenomenon of the gender digital divide in South Africa. The study explores new
\end{abstract}


antecedents of the digital gender divide that influences motivation of women to participate in the IT sector. This study used a qualitative approach through in-depth interviews of South African women in the IT sector. The rich volume of data collected was analysed via a thematic analysis. The analysis confirmed existing antecedents gleaned from literature and also uncovered three new dimensions, namely, networking, impartial mentorship and HR as motivators for women in the IT sector. The findings of the study also provides for a better understanding on the barriers that perpetuate the unequal gender gap problem especially in managerial and leadership roles.

Keywords: Barriers, Gender digital divide, Gender gap, IT sector, Motivation 


\section{Introduction}

In today's environment, women are not only underrepresented in top leadership positions in organizations but the rate of progress for women career advancement has been slow (Duke, 2017). Among Fortune 500 companies, only two per cent of CEOs were women and men hold $80 \%$ of all national leadership posts (Female Leadership in our Time, 2016). According to the Grant Thornton Business Report (2015), the proportion of the top jobs in business held by women was only $22 \%$ in 2015 . Although women are closing the gap in some critical sectors such as the health sector but the representation of women in leadership is still low, with fewer than only 20\% in leadership positions (Duke, 2017). In South Africa the representation of women in leadership is alarmingly low with $4.4 \%$ as Managing Directors (MDs) and 5.3\% as Chief Executive Officers (CEOs), $15.8 \%$ as company directors and 21.6\% as executive management positions (Businesswomen Association, 2011). An international report in 2015 reports women in leadership roles as only 27\% in South Africa (Grant Thornton Business Report, 2015). Makou, (2017) reported that in terms of earning potential, South African women earn $27 \%$ less than their male counterparts. Saal, (2017) asserted that presently there is only one female CEO in of the Top 40 companies listed on the Johannesburg Stock Exchange. “Global Gender Gap Report” (2017) ranked South Africa as having only 19\% female representation at Boards Directors in publicly traded companies

In the IT Sector in South Africa, there is also a lack of women representation and women constitute only $20 \%$ of the labour force of that sector. Based on a survey by ICASA, (2017), in the technology sector in particular, men outnumber women at every level and more so at the higher levels of leadership. The Report goes on to add that, only $21 \%$ of executives in the technology sector and that women's career advancement in this sector suffers grievously from the gender digital divide problem. Women in South Africa are said to face numerous barriers in breaking into the IT labour force in. South African women make up only $22 \%$ of those with undergraduate degrees in science, engineering, and technology, even though they represent 57\% of all enrolled in university (Women in Global Science and Technology, 2011). According to the ICASA Report (2017), the lack of women in the technology sector discourages other women from entering the field. The employed women feel disempowered to engage with female role models, find mentors or participate in networking.

Research in this area is able to identify several barriers such as cultural beliefs about gender, as well as workplace structure, practices and patterns of interaction (Ely et al., 2011). Studies also suggest that individuals are more likely to hire people like them and female candidates may also be attracted to companies with more women and perceived as having more opportunities for advancement or mentorship (Duke, 2017). Grant Thornton Business Report, (2015) stated that the advancement of women into senior leadership is hampered by barriers of stereotyping such as the women's traditional role of being homemakers. Parenthood is still viewed as a major barrier to female advancement into senior roles. Eagly, (2008) reframed the obstacles for women as a labyrinth rather than the traditional 'glass ceiling'. The authors additionally stated that obstacles to leadership are seen as cumulative and complex for 
women at every career stage. Arekapudi, (2018) further stated that legal barriers are still widespread and in some African countries wherein husbands are legally allowed to prevent their wives from working. Ojokoh et al., (2014) postulated that women entering the IT sector in South Africa face challenges such as work-family balance issues, the undervaluing of women's contributions at work, adverse stereotypes of women and a lack of guidance on career options.

\section{Problem Identification}

Despite advancements in research, women in the technology industry in South Africa hold only 19\% senior management roles (Grant Thornton Report, 2015). Given the current landscape, the Global Gender Gap Report estimates it will be another 217 years before South Africa achieves gender parity (Duke, 2017). Survey by ICASA (2017), alarmingly report that in the technology sector men outnumber women at every level particularly at the leadership. Additionally, the Report also highlights that only $21 \%$ of women hold middle management positions in the technology sector and that women's career advancement suffers seriously from the gender digital divide problem.

Currently, studies have identified general information about factors contributing to low representation of women in the IT sector in South Africa However, there is a lack of in-depth research on the underrepresentation of women in the IT sector in South Africa (Msila, 2013; James et al., 2006).

Much can be learned from a qualitative study that involves representation of women in the IT sector in South Africa. In addition, in light of the broad stagnation of women taking senior leadership roles globally, this study focuses on why women's career paths diverge from those of men in the IT sector in South Africa. As such, there is need to explore and uncover and factors contributing to under-representation of women in IT sector (Arekapudi, 2018). In light of the problems identified in the above section, this research will purport to answer the following research questions.

Research Question One: What are the factors that are perpetuated by the gender digital divide from the perspective of women leaders in the IT sector?

Research Question Two: What are the motivators for women's advancement in the IT sector?

\section{Literature Review}

Researchers have identified several barriers faced by women in the technology sector workforce. The top three barriers identified in the ICASA (2017) report are a lack of female mentors (48\%), a lack of female role models (42\%) and limited networking opportunities (27\%). Some other barriers stated by James et al., (2006) are challenges such as work-family balance issues, the undervaluing of women's contributions at work, adverse stereotypes of women, the relative absence of women role models, difficult re-entry because of the rapid pace of change in IT and a lack of guidance on career options. Researchers' also identified several other barriers such as gender stereotypes, inflexible working hours, inadequate 
childcare, hierarchical structures, and a lack of appropriate mentoring and training (Ham et al., 2011). According to Ellemers, (2014) the key to providing equal career opportunities for women and men in organizations is through acknowledging that this is hard to achieve, due to implicit gender bias. In view of the numerous barriers, organizations must address these barriers by encouraging women to apply for technology roles and retain them.

Several studies have revealed that inflexible working hours and work life practices are one of the barriers in the career progression of women (Bhattacharyya, 2012; Institute for Public Policy and Research, 2014). The Institute for Public Policy and Research, (2014), argued that flexible working hours can overcome barriers that are preventing women from entering the workforce. Another study by Bhattacharyya, (2012) revealed that the majority of IT firms require adherence to 60 working hours per week. This study proposed that the key to attract more female talent in IT sector is through flexible work practices (Bhattacharyya, 2012). However, a study by Kalysh et al., (2016) found that work-life practices had a direct effect on the proportion of women in the IT sector. Tlaiss and Kauser (2011) in their study found that women's responsibilities towards their families were not perceived as barriers hindering their career progress. Therefore, there are some inconsistencies in the research findings related to the role of flexibility in the workplace towards women's career.

Past studies also revealed that organization culture is one of the barriers to women's career development and retention (Tlaiss and Kauser, 2010; Tharenou, 2009). A study by Tlaiss and Kauser (2010) found that organization culture is one of the factors that affected the career progression of women. Martin et al. (2018) also found that gender was a barrier to effective organizational learning. Similarly, Tharenou (2009) further stated that women were underrepresented in managerial positions in part due to gender discrimination. Another study by Coronel et al., (2010) found that certain features of the organizational work culture, which were generally perceived as strongly masculine was one of the factors that contributed to women's advancement in their career. Catanzaro et al., (2010) stated that men were more likely than women to intend to pursue a job with a competitive organization. However, a study by Tlaiss and Kauser (2011) found that some cultures such as Lebanon, women managers do not perceive gender-centered factors as obstacles to career advancement.

Organization support and mentoring was also found to have a positive influence on career advancement of women (Tlaiss and Kauser, 2010; Thurasamy et al., 2011). Tlaiss and Kauser (2010) found that female managers perceive their career progression to be affected by organizational practices. Thurasamy et al., (2011) suggested that 'having a supportive supervisor is very important in career advancement'. Thurasamy et al., (2011) concluded that supervisor support was positively and significantly related to objective career advancement. Findings of a study by Chen, (2016) supported earlier research and confirmed the importance of mentoring relationships for women who aspire to administrative positions. Santamaria and Jaramillo, (2016) also stated that the lack of women in upper-level administration is due to the lack of mentoring. The findings of another study by Crisp and Alvarado-Young, (2018) revealed that women leadership and mentoring play a very important role in the career 
development of women. Therefore, most studies point towards the important role of organization support and mentoring of women.

Researchers also pointed to the importance of training and development to equip specific skill sets or providing a method for improvement in job performance of women (Francis, 2017; Smith, 2006). Francis, (2017) stated that the objective was to assist women to gain knowledge and necessary skills in an evolving IT setting that can enhance job performance and support their career advancement. McBride, (2011) asserted that line managers should encourage women's participation along career pathways through workplace education and training. Eagly, (2005) asserted that the training of women for leadership should focus on the relational aspects of achieving authenticity as a leader. Smith, (2006) further stated that training in workplaces can address the barriers faced by women through acknowledgement of cultural barriers, improving self-confidence and providing motivation. However, a study by Tourish, (2012) showed that women are more resilient leaders and possess higher levels of Leadership Resilience Profile skills than men. Therefore, there is overwhelming support towards provision of training for women.

Career ambition and advancement is another factor that affects women in their leadership roles. Women encounter and navigate difficulties that their male counterparts do not encounter in their career paths due to implicit gender bias (Eagly, 2008). According to a study by “Ambition and Gender at Work” (2011), women managers are hampered in their careers by lower ambitions and expectations. The study stated that women often lack self-belief and self-confidence and this further leads to lower risk taking and more cautious career choices. Furthermore, on average, women lag three years in accepting leadership and management positions as compared to men (Institute of Leadership and Management, 2011). One of the explanations for gender differences in career development is that organizations tend to favor male over female employees (Williamson and Wilkie, 2015). There are other barriers that may originate in organizational cultures, expectations, and everyday practices that unintentionally favor men over women (Williamson and Wilkie, 2015). As explained by Williamson and Wilkie (2015), implicit gender bias is widespread and hard to avoid.

Research has also revealed that the use of women's networks is emerging as one method of advancing women's careers within organizations (Huang and Aaltio, 2014; Cross and Linehan, 2006). The results of a study by Tlaiss and Kauser (2010) revealed that one of the predictors of female managers' career progression is networks. Cross and Linehan, (2006) considers networking as an essential aspect of organizational culture and longevity. Cross and Linehan, (2006) regarded networking as a vital tool for women to increase visibility toward senior levels and gain greater access to support and mobility. The results of a study by Huang and Aaltio, (2014) that was based on composition and structure of the networks found that there is an effect of female-to-male dyads, which are mainly within power- and work-related networks while female-to-female dyads are mostly 'social'. However, some women's networks have been perceived negatively and some networks are viewed as 'have-a-chat-clubs' (Pini et al., 2004). 
The essentialist theory and social construction theory can be applied to explain the under-representation of women in IT professions. Essentialist theory posits that men and women have fixed and different natures and Adya, (2008) stated that biological and psychological differences explain women's participation in the IT workforce. Venkatesh et al., (2000) stated that differences in women's IT response were related to computer aptitude and anxiety. The assumption based on the essentialist theory is that men have biological or psychological characteristics that make them more suitable to work in the IT sector. According to the social construction theory, human actions are the product of the culture in which people live (Berger and Luckmann, 1966). Adya and Kaiser, (2005) found that fathers were one of the influences on girls choosing to enter the IT workforce. Another study by Adya, (2008) provided further support of social influences on female participation in the IT sector.

\section{Methodology}

This research adopted the interpretivism philosophy. Interpretivists contend that only through the subjective interpretation of and intervention in reality can that reality be fully understood and the study of phenomena in their natural environment is key to the interpretivist philosophy (Saunders et al., 2015). This research is based on inductive approach and the purpose here was to get a feel of what was going on, so as to understand better the nature of the problem (Saunders et al., 2012). This is a phenomenological research and as stated by Creswell (2014), it is a strategy of inquiry in which the researcher identifies the essence of human experiences about a phenomenon as described by participants. Guided by the phenomenological research paradigm, this research uses qualitative research to explore the barriers faced by women in South Africa. A qualitative research using semi- structured interview was chosen. This method allowed the researcher to have a deeper understanding of the research area by taking into account the perspective of the study population and the context in which they live (Saunders, et al., 2015). While conducting the study in a natural setting, the researcher built a holistic picture, and analysed the words of the respondents, in order to construct a detailed view of the information (Creswell, 2013).

This study utilised a sample population of South African female executives working in the IT sector. For phenomenological studies, Creswell, (2013) recommends five to 25 respondents and the number of respondents is sufficient to the point at which the data gathered begin to be redundant (Creswell, 2013). The sample size for this study was six respondents. See Table 1 below for the respondents' profile. Purposive sampling was used to select he participants. In resonance with the qualitative approach, six women working in the IT sector in South Africa were interviewed. The interview questions were constructed prior to the interview process. However, due to the broad subject matter, a semi-structured approach was adapted to allow follow-up questions. Audio recordings were utilized under the consent of the participants to permit a smooth interview process as well as done to ensure accurate findings. 
Table 1. Participant Profile

\begin{tabular}{|l|l|l|l|l|l|l|l|}
\hline No & Name & Position & Profile & $\begin{array}{l}\text { No. of } \\
\text { employee }\end{array}$ & $\begin{array}{l}\text { Marital } \\
\text { Status }\end{array}$ & $\begin{array}{l}\text { Parental } \\
\text { Status }\end{array}$ & Qualification \\
\hline 1 & S & IT Audtior & $\begin{array}{l}\text { Female, 30-35, black } \\
\text { South African }\end{array}$ & Over 2,000 & No & No & $\begin{array}{l}\text { Bachelors } \\
\text { degree }\end{array}$ \\
\hline 2 & O & $\begin{array}{l}\text { IT } \\
\text { programmer }\end{array}$ & $\begin{array}{l}\text { Female, 25-30, black } \\
\text { South African }\end{array}$ & Over 2,000 & Yes & Yes & $\begin{array}{l}\text { Bachelors } \\
\text { degree }\end{array}$ \\
\hline 3 & $\mathrm{R}$ & $\begin{array}{l}\text { System } \\
\text { Analyst }\end{array}$ & $\begin{array}{l}\text { Female, 25-30, black } \\
\text { South African }\end{array}$ & 0ver 200 & No & Yes & $\begin{array}{l}\text { Bachelors } \\
\text { degree }\end{array}$ \\
\hline 4 & A & $\begin{array}{l}\text { Business } \\
\text { Analyst }\end{array}$ & $\begin{array}{l}\text { Female,30-35, black } \\
\text { South African }\end{array}$ & $\begin{array}{l}\text { Less than } \\
\text { 200 }\end{array}$ & Yes & Yes & $\begin{array}{l}\text { Bachelors } \\
\text { degree }\end{array}$ \\
\hline 5 & $\mathrm{~N}$ & $\begin{array}{l}\text { Senior } \\
\text { Professor, IT }\end{array}$ & $\begin{array}{l}\text { Female, 35-40, black } \\
\text { South African }\end{array}$ & Over 200 & Yes & Yes & PhD \\
\hline 6 & $\mathrm{Z}$ & $\begin{array}{l}\text { Associate } \\
\text { Professor, IT }\end{array}$ & $\begin{array}{l}\text { Female, 30-35, } \\
\text { Caucasian. S. Africa }\end{array}$ & Over 200 & No & No & PhD \\
\hline
\end{tabular}

This research applied the 'manual thematic coding analysis' strategy extrapolated from the participants in the interview process. This technique is crucial toward developing key links and relationships to support the theory, as well as 'aiding the researcher to avoid importing existing theory into the analysis', (Willig, 2013) thus avoiding repetition and creating a more accurate theory basis. According to Sekaran and Bougie, (2016) the thematic analysis is a highly recommended method as it allows for thorough data analysis and particularly effective method in respect to business and social sciences. Bloor and Wood, (2006) describe the thematic analysis as the interpretation of trends and patterns in data. In addition, the frequency of usage, and relationships to formulate a 'systematic coding and categorizing approach' from the patterns are documented. Through this process of identification, themes were formed out of repetitive data findings, then numbered and categorised into the corresponding theme. Emerging themes also contribute to the category and analysed according to existing data documented in the literature review.

\section{Results}

To address the central research question, this study relied on interviews with women engaged in the IT sector regarding their perceptions of challenges and barriers. The thematic analysis of the information obtained revealed several findings about the digital divide faced by women in South Africa. Based on the findings, new constructs identified.

\subsection{New Constructs}

\subsubsection{Networking}

Participants recognized networking to be an important factor among others, however 
specifically in the context of organisational culture. Participants found networking opportunities and capabilities to stem from presence and normality of networking in the organisation, which has largely been reported as informal and not particularly inclusive.

'Smokers tend to rise higher than non-smokers because smokers go outside, form relationships. You don't have to be a smoker per se, but it does help in being close to people and having the same language and personality types. You could say anybody is welcome, but you have to have a strong impression, and make a concerted effort.' (OE 1; 5)

The highlight of this particular aspect was that although women don't factor this in at the highest priority, they observed it on a cultural and organisational level in terms of an aspect that they were not privy or readily invited. However, whether by choice or circumstance this revealed their desire for the privilege and ease with which to pursue this factor without partaking in its' traditionally kept male customs.

\subsubsection{Impartial Mentorship}

The majority of participants cite mentorship as a key enabler for women's advancement whilst also maintaining that mentors and the 'mentor-mentee' relationship should not be gender based rather based on collaboration, and organic development.

'I don't think it should matter whether it's female or male. I'd like to say that rather it should be committed individuals guiding you in a mentorship aspect. I was mentored by a male, he was my research supervisor. He was really supportive and he was very invested in me. I don't know whether I would have benefitted more had it been a woman and sometimes also women compete.' (NA 3.3)

Careful selection is the primary criteria regardless of formal or informal settings to enhance the likelihood of successful mentors and protégés. Young and Perrewe, (2000) cited by Fulmer et al., (2012) further report that by doing so, individuals with shared values and common goals procure pairings committed to sustain long-term relationships. Therefore it wise to allow mentors and protégés some input into the pairing process.

\subsubsection{Role of HR (Human Resources)}

In terms of managerial advancement, the study initially found top management as the primary perpetrator toward the lagging of women's advancement, a number of participants acknowledge the role of HR as a contributing factor to this cause.

'I also think that HR also has a role in that they are supposed to be monitoring and have what I'll call 'indicators' that show the recruitment process, in terms of the type of people hired and statistics of the hires.' (AA: 5.4)

The gathered quotes echo a number of women's beliefs that advancement should be a fully supported and organisation led initiative on all levels. This is especially the case for organisations that implement quotas and targets in order to not only hire talent but develop them across the board. 
In aide of the contribution of the enriched conceptual framework and overall interview findings, the research questions were each answered and analysed respectively.

5.2 Research Question One: What are the Factors that are Perpetuated by the Gender Digital Divide?

\subsubsection{Stereotyping}

In South Africa, the culture is patriarchal and as a reflection of that major organisations and particularly the context of the IT industry, are designed by men and male-dominated. As a result, women are considered 'less tech savvy, and more technophobic, and because the technology is not built for their needs and intuition.' (Hilbert, 2011) This perception plagues women's ability towards conducive learning and prominent participation in these spaces.

$\mathrm{N}$, an IT professor found that at an educational level in terms of programming, female students had the capability to complete tasks however had a 'conflict of confidence' in terms of their abilities to take on the technical tasks and be equally viable employees.

'Already it's a male dominated field. I think from development roles there's a mentality that it's for men. Women have to convince them that they can do it and have to prove a lot more. It's a stereotyping of women.' (NA 1.3)

In South Africa, women's roles in the household are disproportionate to men where they hold maternal roles such as care giving, cooking, cleaning and physical activities including fetching water (Chetty et al., 2018). A participant noted this maternal role specifically affecting employment opportunities as it pertains to women stating:

'Stereotyping happens often. I've heard stories of women that didn't get a role because they (recruiters) are less likely to hire females that indicated they were likely or wanted to start families. In my experience, I think it happens a lot particularly women who had taken maternity leave, and maybe even single mothers.' (AA 1.5)

As a result, this drives women to apply more effort to be seen and fight against stereotypes that are not of their own creation, which in turn prove to be a challenge in the IT industry. In what is called as the 'motherhood assumption' is a barrier to career success in IT and some men also believe that motherhood can be a barrier for women in IT (Hillbert, 2011)

\subsubsection{Biasness in Recruitment}

This prejudice extends to the recruitment process wherein traditional systems of hiring and seeking talent are still narrow and largely directed toward males, favourably white males. The bias is apparent as the Department of Labour Republic of South Africa (2016) reported that white men alone represent $42 \%$ of recruits.

By this perception and the privilege of digital exposure, white men have a disproportionate advantage, which plays into the stereotyping of other types of people primarily, black people and women. A participant noted that: 
'In my experience it (stereotyping) does play a role from the South African demographic. Programming, is mainly white males who are introduced to it early in high school so they get preference because of perception of having knowledge of more experience whilst black people male or females learn in varsity. So white male get preference because they seem to know more. I would suggest a blind applicant review system by redacting names and gender identification in the CV and having a diverse mix of interviewers.' (OE 1:3)

The notion of 'seeming to know more' may be attributed to the varying socio-economic differences it is largely reported to be influenced by these dominant gatekeepers. This is cited by Mishra and Aneja, (2017) as 'opportunity hoarding' which occurs when those in dominant positions men primarily white, preserve and hold on to job resources for their own group.

\subsubsection{Managerial Advancement and Gender Parity}

In accordance with recruitment, the top down and bottom up approach alike play a role from state of top management and HR were managerial advancement is concerned and similarly broadened by the divide. With the exception of two respondents; $\mathrm{N}$ and $\mathrm{Z}$ (from the same organisation), the findings show a lack of gender parity in leadership positions and existing barriers where promotion is concerned. The findings regard the stereotype 'motherhood assumption' also existing in this instance:

'The one barrier I can see is continuity. In terms of child-bearing when someone has a child their out for three to four months you may get overlooked. And people tend to hire people in their circles, if female is not in circles'(OE 5.1)

A fellow participant provides anecdotal evidence of a case in the organisation as it relates to why this makes representation makes it harder for women to progress:

'A colleague of mine, she was a senior associate and got promoted to assistant manager. She was there for a long time and I think she only got promoted and even before this time she had two kids, and took two maternity leaves where she ended up spending six months. As a result, instead of getting promoted to manager after two years she got promoted to manager after something like three to four years. So lack of representation remains of course.'(SI 5.1)

5.3 Research Question Two: What are the Motivators for Women'S Advancement in the IT Sector?

\subsubsection{Mentorship}

Mentorship experiences varied amongst participants, however it was favoured as a fruitful factor in this study. The presence of gender disparity were not readily re-enforced to a certain extent hence the presence of 'impartial mentorship' in the enriched framework. Its importance was proven worthwhile since the nature of these relationships, effectiveness is attributed to employee awareness and be integration into the culture. According to one of the findings,

'It's not effective, it would be more effective if people knew what it and it was part of the organisational culture. What would help is also knowing that your mentor views your input to 
the company seriously and really makes an impartial effort.' (NA 3.3)

The study found the merit of mentorship to be attributed to help navigate professional and personal struggles, general advice including financial and career progression as well as related by a participant.

'It's very important because you can get the right information for your skillset and information and knowledge sharing but we need someone who will mentor the women and take us seriously.' (AA 3.2)

Knowledge sharing has numerous benefits for women in IT including the risk of isolation that results in exclusion in social networks of peers and decision makers that typically arises in male dominated spaces (Aschraft et al, 2016). Russell and Lepler, (2017) lament that by breeding this connectedness, women may also face less silencing.

\subsubsection{Flexible Hours}

According to existing literature, flexible hours are a substantial motivating factor for women, as was validated based on the findings in this study. Flexibility is a vital motivator that informs women's satisfaction in both professional and personal circumstances. Professionally, it is a keen priority for productivity, and particularly retention.

'It's probably the most important factor. I know I can be anywhere else but having that freedom and being able to basically work from home is the only reason I've stayed as long as I have.' (ZI 4.2)

The mobility afforded by flexible hours also plays into the new theme of networking toward increasing women's social mobility, which can allow them to make connections, and pursue avenues such as training to improve themselves. According to Martin and Barnard, (2013) more workplace participation furthers 'financial autonomy, greater mobility and their larger social acceptance in male dominated society.' As their presence is recognised and varied across the industry, it bridges the gap to of women's occupancy as the new norm.

The significance of this motivator is also accredited to the maternity and paternity policies. These policies are shaped by industry and not governmental standards and so flexibility plays a role in women's choice of retention and career progression. The standards are largely three to four months paid leave, with varying conditions of repayment. In one circumstance, women have to be employed for a year at the organisation prior to getting pregnant and being permitted maternity leave:

'It's fair in terms of paying back the time on leave but the condition of working a year before getting pregnant, especially as sometimes you can't plan or predict the timing of things like that is a bit unfair.' (AA 4.4)

\subsubsection{Training}

As far as training goes, this motivator is availed as a valuable element for women's 
development in the IT industry for various reasons including, expanding skillset and On-the-job training specifically was mentioned in preventing stagnancy either in job position and job performance. By organisations providing programs to cultivate this, women are able to expand their competencies in different roles. One response read:

'Yes, it's very important to leverage your skillset and facilitate advancement particularly in IT.' (AA 2.2)

In this respect, it provides a tool for women to be a competitive commodity in the job market this in turn allows women equal footing in the job market, which is imperative as Francis, (2017) notes this as crucial to gain more financial rewards as well. In agreement with this a participant described:

'Yes, it's important. If there's training there's space to grow so I take it into consideration. There's something I can learn, I can add more qualification and up my marketability.' (OE: 2.2)

\section{Implications}

From the theoretical perspective, the findings of this study provide a new perspective to understand the complexities related to challenges faced by women and the motivators in their career in South Africa. The findings will provide theoretical and practical implications for the career advancement of women and offers an alternative viewpoint to examine challenges and motivators for women. Most importantly, this research adds to the literature on career advancement of women specifically in the IT sector in South Africa. This research also provides practical advice that may assist successful career advancement of women. The evidence from this study contains practical implications for companies in selecting, training, motivating and providing support to women in the IT sector. Hence, human resource managers should consider addressing the barriers that encompass stereotyping, biasness in recruitment policies and discrimination. This study suggests that achieving higher career advancement of women in the IT sector will entail provision of training, flexible working hours and providing mentorship. Organization policymakers can implement policies to increase the recruitment of women and offer training and mentorship to retain them. In addition, organizations to actively give qualified women leadership opportunities and put in place aspirational career paths for women at work.

\section{Conclusion}

This study helped to identify new antecedents that added to the existing body of knowledge on the dimensions that influence South African women's motivation to participate in the IT sector. The role of networking, impartial mentorship and HR policies were identified as being a pivotal role in creating equal opportunity gender participation. This research therefore, has examined the neglected viewpoint of a key stakeholder namely South African women in the IT sector, the findings of which then formed the basis of an enriched model. This revised model details the underlying social structures to explain the key stakeholder viewpoints of the 
gender digital divide in South Africa. The enriched model does more than just extend current understandings of the gender digital divide; it provides a new working framework for use in practice. Despite the significant findings of this study, there are some limitations. Firstly, the respondents were considered mostly a homogenous community, and differences in age, ethnicity and background were not taken into consideration. The perception and attitudes toward women in leadership positions may vary based on differences in culture, age and ethnicity. A further limitation of the study was the restriction of the study in the IT sector in South Africa and as in any exploratory study; the results may have limited generalizability. Furthermore, it is acknowledged that the sample size of six interviewees for this study is not large. These limitations of this study provide directions for future research. For future studies, a study with bigger sample can be undertaken. In addition, ccontrasting between private and public sector organizations may reveal differences in the perception of women in South Africa. A mixed method approach is which can be either an explanatory sequential approach or an exploratory sequential approach is recommended to obtain and more in-depth information.

\section{References}

Abdullah, N., Bakar, N. and Abdullah, H. (2013). Fertility Model and Female Labour Force Participation in Selected ASEAN Countries. Journal of Economics, Business and Management.

Adya, M. (2008). Women at work: Differences in IT career experiences and perceptions between South Asian and American women. Human Resource Management, 47(3), pp.601-635.

Adya, M. and Kaiser, K. (2005). Early determinants of women in the IT workforce: a model of girls' career choices. Information Technology \& People, 18(3), pp.230-259.

Arekapudi, N. (2018). How to promote gender equality in Afghanistan. World Economic $\begin{array}{lllll}\text { Forum. } & \text { Retrieved } 22 & \text { Jun, } & \text { from }\end{array}$ https://www.weforum.org/agenda/2015/06/how-to-promote-gender-equality-in-afghanistan/

Ashcraft, C., McLain, B., \& Eger, E. (2016). Women in Tech: The Facts.” [ebook] National Centre for Women \& Technology (NCWIT). Retrieved 22 Jun, 2018, from https://www.ncwit.org/sites/default/files/resources/ncwit_women-in-it_2016-full-report_final -web06012016.pdf

Berger, P., \& Luckmann, T. (1967). The social construction of reality. New York City USA: Anchor Books.

Bhattacharyya, A. (2012). Women in Indian Information Technology (IT) sector: a Sociological Analysis. IOSR Journal of Humanities and Social Science, 3(6), 45-52.

Bizcommunity.com. (2011). 2011 BWA South African Women in Leadership census out. Retrieved 22 Jun, 2018, from http://www.bizcommunity.com/Article/196/19/58080.html 
Bloor, M., \& Wood, F. (2006). Keywords in qualitative methods. London: SAGE.

Catanzaro, D., Moore, H. and Marshall, T. (2010). The Impact of Organizational Culture on Attraction and Recruitment of Job Applicants. Journal of Business and Psychology, 25(4), 649-662.

Chen, Y. (2016). Mentoring female assistant professors enhances their success. Communications of the ACM, 59(12), pp.40-42.

Chetty, K., Aneja, U., Mishra, V., Gcora, N., \& Josie, J. (2018). Bridging the digital divide in the G20: skills for the new age. Economics: The Open-Access, Open-Assessment E-Journal.

Clark, A., \& Sekher, T. (2007). Can Career-Minded Young Women Reverse Gender Discrimination? A View from Bangalore's High-Tech Sector.” Gender, Technology and Development, 11(3), 285-319.

Connor, H., \& Shaw, S. (2008). Graduate training and development: current trends and issues.” Education + Training, 50(5), 357-365.

Coronel, J., Moreno, E., \& Carrasco, M. (2010). Work-family Conflicts and the Organizational Work Culture as Barriers to Women Educational Managers. Gender, Work \& Organization, 17(2), 219-239.

Creswell, J. (2013). Educational Research: Planning, Conducting, and Evaluating Quantitative and Qualitative Research. 5th ed. Harlow, United Kingdom: Pearson Education Limited.

Crisp, G., \& Alvarado-Young, K. (2018). The Role of Mentoring in Leadership Development.” New Directions for Student Leadership, 2018(158), 37-47.

Cross, C., \& Linehan, M. (2006). Barriers to advancing female careers in the high-tech sector: empirical evidence from Ireland. Women in Management Review, 21(1), 28-39.

Department of Labour Republic of South Africa (2015). Commission for Employment Equity Annual Report 2015-2016. [online] Pretoria: Department of Labour Chief Directorate of Communication. $\quad$ Retrieved 22 Jun, 2018, from http://www.labour.gov.za/DOL/downloads/documents/annual-reports/employment-equity/201 5-2016/16th\%20CEE\%20Report.pdf

Duke, S. (2017). The key to closing the gender gap? Putting more women in charge. World Economic Forum. $\quad$ Retrieved 22 Jun, 2018, from https://www.weforum.org/agenda/2017/11/women-leaders-key-to-workplace-equality/

Eagly, A. (2005). Achieving relational authenticity in leadership: Does gender matter?” The Leadership Quarterly, 16(3), 459-474.

Eagly, A. (2008). Women and the labyrinth of leadership. Human Resource Management International Digest, 16(1). 
Ellemers, N. (2014). Women at Work. Policy Insights from the Behavioral and Brain Sciences, 1(1), 46-54.

Ely, R., Ibarra, H., \& Kolb, D. (2011). Taking Gender Into Account: Theory and Design for Women's Leadership Development Programs. Academy of Management Learning \& Education, 10(3), 474-493.

Europeanbusinessreview.com. (2016). Female Leadership in our time. Retrieved 22 Jun, 2018, from

http://www.europeanbusinessreview.com/wp-content/uploads/2016/04/Female-Leaderhip-InOur-Time-2016-2.pdf

Francis, V. (2017). What influences professional women's career advancement in construction?”. Construction Management and Economics, 35(5), 254-275.

Fulmer, C., \& Gelfand, M. (2011). At What Level (and in Whom) We Trust: Trust Across Multiple Organizational Levels. SSRN Electronic Journal.

Grant Thornton. (2015). Women in business: The Path to Leadership. Retrieved 22 Jun, 2018, from http://www.grantthornton.global/en/insights/articles/women-in-business-2015

Ham, C., Clark, J., Spurgeon, P., Dickinson, H., \& Armit, K. (2011). Doctors who become chief executives in the NHS: from keen amateurs to skilled professionals. Journal of the Royal Society of Medicine, 104(3), 113-119.

Hilbert, M. (2011). Digital gender divide or technologically empowered women in developing countries? A typical case of lies, damned lies, and statistics. Women's Studies International Forum, 34(6), 479-489.

Huang, J., \& Aaltio, I. (2014). Guanxi and social capital: Networking among women managers in China and Finland. International Journal of Intercultural Relations, 39(1), 22-39.

Institute for Public Policy and Research (2014). Women and flexible working. Improving female employment outcomes in Europe. Scotland: The Progressive Policy Think Tank, p.23. $\begin{array}{llll}\text { Retrieved } 22 & \text { Jun, from }\end{array}$ https://www.ippr.org/publications/women-and-flexible-working-improving-female-employme nt-outcomes-in-europe

Institutelm.com. (2011). Ambition and gender at work. Retrieved 22 Jun, 2018, from https://www.institutelm.com/resourceLibrary/ambition-and-gender-at-work.html

Isaca.org (2017). Women In Technology Survey | Breaking Gender Barriers | ISACA. Retrieved $22 \quad$ Jun, 2018, from http://www.isaca.org/info/2017-women-in-technology-survey/index.html

Kalysh, K., Kulik, C., \& Perera, S. (2016). Help or hindrance? Work-life practices and women in management. The Leadership Quarterly, 27(3), 504-518. 
Makaou, G. (2017). Do South African women earn 27\% less than men? | Africa Check. Africa Check. 22 Retrieved Jun, 2018, from https://africacheck.org/reports/south-african-women-earn-27-less-men/

Martin, P., \& Barnard, A. (2013). The experience of women in male-dominated occupations: A constructivist grounded theory inquiry. SA Journal of Industrial Psychology, 39(2).

McBride, A. (2011). Lifting the Barriers? Workplace Education and Training, Women and Job Progression. Gender, Work \& Organization, 18(5), 528-547.

Mishra, V., \& Aneja, U. (2017). Empowering women in a digital age in South Africa” | ORF. [online] ORF. $\quad$ Retrieved 22 Jun, 2018, from https://www.orfonline.org/research/digital-age-south-africa-empowerment-women/

Msila, V. (2013). Obstacles and Opportunities in Women School Leadership: A Literature Study. International Journal of Educational Sciences, 5(4), 463-470.

Ojokoh, B., Adeola, O., Isinkaye, F., \& Abraham, C. (2014). Career Choices in Information and Communication Technology among South Western Nigerian Women. Journal of Global Information Management, 22(2), 48-77.

Pini, B., Brown, K., \& Ryan, C. (2004). Women-only networks as a strategy for change? A case study from local government. Women in Management Review, 19(6), 286-292.

Russel, M., \& Lepler, L. (2018). How We Closed the Gap Between Men's and Women's Retention Rates.” [online] Harvard Business Review. Retrieved 22 Jun, 2018, from https://hbr.org/2017/05/how-we-closed-the-gap-between-mens-and-womens-retention-rates

Saal, P. (2017). Women still under-represented in positions of authority and power.” [online] Times Live. 22 Retrieved Jun, 2018, from https://www.timeslive.co.za/news/south-africa/2017-08-21-women-still-under-represented-inpositions-of-authority-and-power/

Santamaría, L., \& Jaramillo, N. (2014). Comadres among Us: The Power of Artists as Informal Mentors for Women of Color in Academe.” Mentoring \& Tutoring: Partnership in Learning, 22(4), 316-337.

Saunders, M., Lewis, P., \& Thornhill, A. (2015). Research methods for business students. 7th ed. Harlow, United Kingdom: Pearson Education Ltd.

Sekaran, U., \& Bougie, R. (2016). Research methods for business. 7th ed. Sussex, United Kingdom: John Wiley and Sons.

Skinner, N., \& Pocock, B. (2011). Flexibility and Work-Life Interference in Australia.” Journal of Industrial Relations, 53(1), 65-82.

Smith, E. (2006). A woman's work is never certificated? How the implementation of nationally recognised training in workplaces helps women get qualifications. Journal of 
Vocational Education \& Training, 58(4), 531-549.

Tharenou, P. (2009). Women's Self-Initiated Expatriation as a Career Option and Its Ethical Issues. Journal of Business Ethics, 95(1), 73-88.

Thurasamy, R., Lo, M., Yang Amri, A., \& Noor, N. (2011). An analysis of career advancement among engineers in manufacturing organizations. International Journal of Commerce and Management, 21(2), 143-157.

Tlaiss, H., \& Kauser, S. (2010). Perceived organizational barriers to women's career advancement in Lebanon." Gender in Management: An International Journal, 25(6), 462-496.

Tourish, D. (2012). Developing leaders in turbulent times. Organizational Dynamics, 41(1), 23-31.

Venkatesh, V., Morris, M., \& Ackerman, P. (2000). A Longitudinal Field Investigation of Gender Differences in Individual Technology Adoption Decision-Making Processes.” Organizational Behavior and Human Decision Processes, 83(1), 33-60.

Willig, C. (2008). Introducing Qualitative Research In Psychology. Milton Keynes: Open University Press.

World Economic Forum. (2015). How to encourage women into the workforce.” [online] Retrieved $22 \quad$ Jun, 2018, from https://www.weforum.org/agenda/2015/03/how-to-encourage-women-into-the-workforce/

World Economic Forum. (2017). The Global Gender Gap Report. Retrieved 22 Jun, 2018, from https://www.weforum.org/reports/the-global-gender-gap-report-2017

Young, A., \& Perrewé, P. (2000). What Did You Expect? An Examination of Career-Related Support and Social Support Among Mentors and Protégés. Journal of Management, 26(4), 611-632

\section{Copyright}

Copyright for this article is retained by the author(s), with first publication rights granted to the journal.

This is an open-access article distributed under the terms and conditions of the Creative Commons Attribution license (http://creativecommons.org/licenses/by/4.0/). 